\title{
High temperature stable piezoelectric, barrier and insulation coatings for sensor applications
}

Bartzsch, Hagen

Fraunhofer FEP

Winterbergstr. 28, 01277 Dresden

\begin{abstract}
The paper presents $\mathrm{AIN}, \mathrm{Al}_{2} \mathrm{O}_{3}, \mathrm{SiO}_{2}$ and $\mathrm{Si}_{3} \mathrm{~N}_{4}$ films deposited by reactive magnetron sputtering at high deposition rates of $200 \mathrm{~nm} / \mathrm{min}$. The deposited AIN films show a strong c-axis orientation and a piezoelectric coefficient $\mathrm{d}_{33}$ of $7 \mathrm{pm} / \mathrm{V} . \mathrm{Al}_{2} \mathrm{O}_{3}, \mathrm{SiO}_{2}$ and $\mathrm{Si}_{3} \mathrm{~N}_{4}$ films and their combinations are excellent insulation films on both metal and silicon substrates. High insulation strength of up to $800 \mathrm{~V}$ was measured at room temperature and at high temperatures of $400^{\circ} \mathrm{C}$. These films perform also well as barrier films. Water vapor transmission rate (WTR) of $\mathrm{Al}_{2} \mathrm{O}_{3}$ is for example $10^{-2} \mathrm{~g} /\left(\mathrm{m}^{2 *} \mathrm{~d}\right)$. Stability of the films during heat treatment at $800^{\circ} \mathrm{C}$ was shown. In the paper example of applications in pressure sensors and material testing are given
\end{abstract}

\section{Introduction}

High temperature stability is a requirement on thin films for some sensor and actor applications. Requirements on the maximum use temperature vary considerably. They may range from $200^{\circ} \mathrm{C}$ for application in process control for injection molding, over $400 \ldots 600^{\circ} \mathrm{C}$ for direct measurements in the combustion chamber or exhaust line of combustion engines up to $800^{\circ} \mathrm{C}$ for turbine applications or up to $1200^{\circ} \mathrm{C}$ for special heating applications.

In the paper examples of high temperature stable dielectric films deposited by reactive pulse magnetron sputtering are given. Due to the high deposition rates that can be achieved, reactive sputtering process is especially suitable for producing rather thick layers.

Required film properties are for example high breakdown field strength, high insulation resistivity, high area yield, high piezoelectric coefficient, resistance to aggressive media, a satisfactory mechanical load limit, effective permeation barriers, good adaptation of the coefficients of expansion to the substrate, dielectric strength (also in contact with electrolytes) and resistance of the layer in downstream processing steps such as laser trimming or wet-chemical etching processes. The coating costs must also be in reasonable proportion to the value of the end-product, meaning that there is often a demand for high deposition rates. The paper will not address the challenges of packaging for high temperature applications.

\section{Deposition technology}

Film deposition was carried out by stationary pulse magnetron sputtering (PMS). The Double Ring Magnetron DRM 400 of Fraunhofer-Institut für Elektronenstrahl- und Plasmatechnik (FEP) was used as the sputter source. This type of magnetron combines two concentric discharges on two separate targets in one magnetron source [1]. Film thickness uniformity of up to $\pm 1 \%$ across an 8 " wafer $(200 \mathrm{~mm})$ is achieved by superposition of the film thickness distributions of these two discharges (Fig. 1).

During reactive sputtering, insulating deposits on plasma shields and on the target edges may charge up and result in unwanted arcing. Therefore, pulse powering was applied in order to regularly discharge the surfaces of insulating deposits and hence ensure the long term stability of the process, even at high powers up to $10 \mathrm{~kW}$. For this the pulse unit UBS-C2 (FEP) was used. This converts the dc power of two dc power supplies into current pulses for each target.

Deposition experiments were carried out by unipolar and bipolar pulse sputtering in the mid-frequency range $(50 \mathrm{kHz})$ from metallic $\mathrm{Al}$ or Si targets. In the unipolar mode (Fig. 2a), pulse powering having negative polarity is applied between each of the targets and the common anode. This anode is not sputtered. In the bipolar mode (Fig. 2b), pulse powering with alternating polarity is applied between the two targets 
that act alternately as cathode and anode of the discharge. Due to the higher power at the outer target compared to the inner target, the bipolar powering is asymmetric.

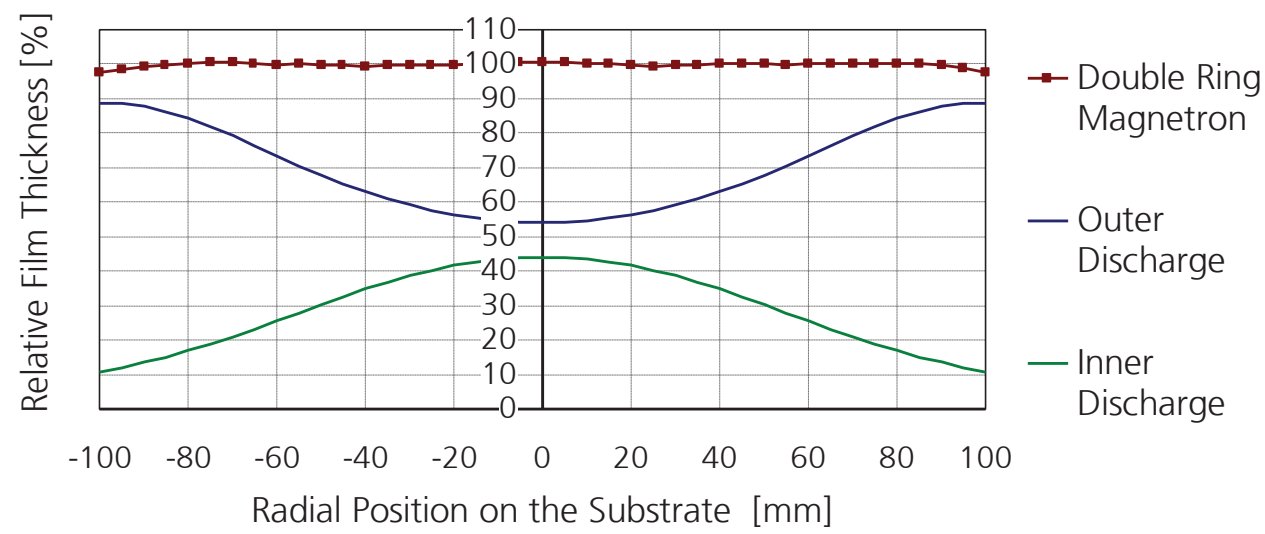

Fig. 1: Film thickness distribution across the substrate for inner and outer ring of the Double Ring Magnetron DRM 400
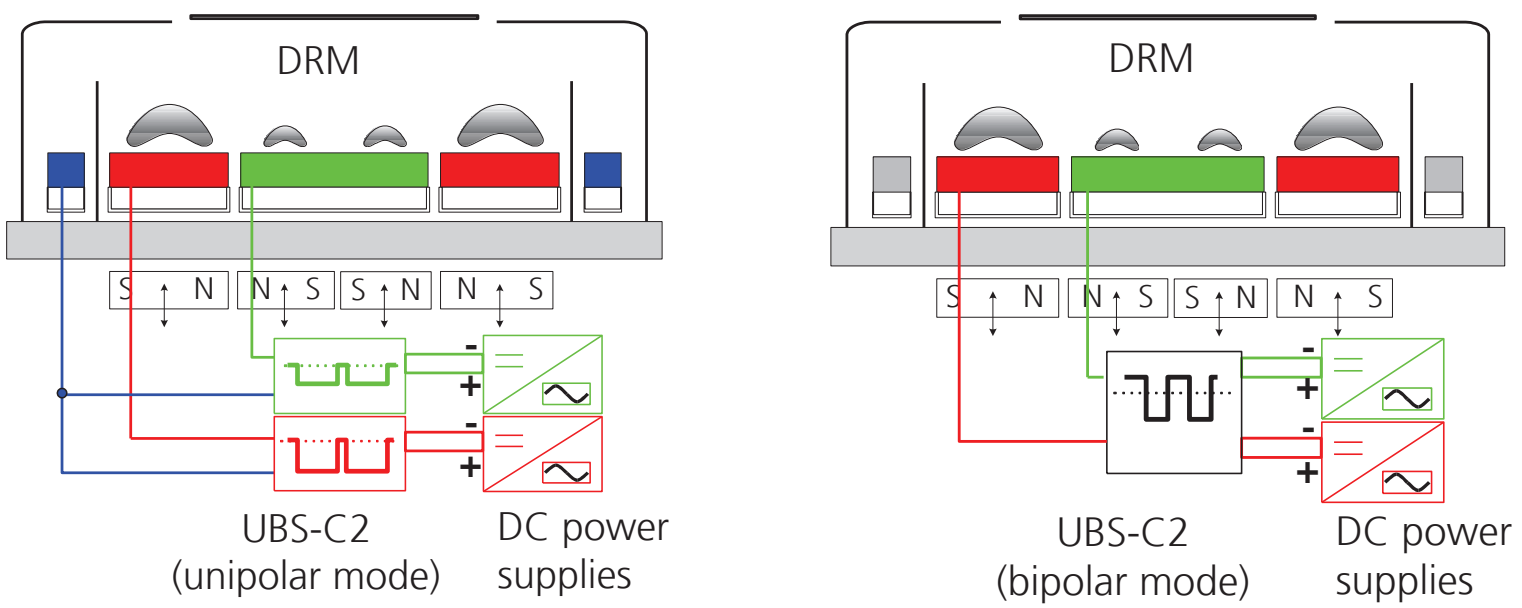

Fig. 2: Unipolar and bipolar pulsed operation of the Double Ring Magnetron

Table 1: Electron temperature and plasma density in unipolar and bipolar pulse mode, $\mathrm{SiO}_{2}$ deposition at $7,5 \mathrm{~kW}$

\begin{tabular}{|l|l|l|l|}
\hline & Electron temperature $T_{e}$ & Plasma density $n_{e}$ & Thermal substrate load \\
\hline Unipolar pulse mode & $10 \mathrm{eV}$ & $1,8^{*} 10^{10} \mathrm{~cm}^{-3}$ & $0,15 \mathrm{~W} / \mathrm{cm}^{2}$ \\
\hline Unipolar pulse mode & $6 \mathrm{eV}$ & $11^{*} 10^{10} \mathrm{~cm}^{-3}$ & $0,75 \mathrm{~W} / \mathrm{cm}^{2}$ \\
\hline
\end{tabular}

In unipolar and bipolar pulse mode here are significant differences in plasma density, electron temperature and hence energetic substrate bombardment (Table 1). In unipolar pulse mode there is an intermediate plasma density, a moderate energetic substrate bombardment and a low thermal substrate load. This is especially suitable for coating temperature sensitive substrates. In bipolar pulse mode there is a high plasma density, hence a strong energetic substrate bombardment and a high thermal substrate load. This can be used to achieve highly dense films [2].

In unipolar as well as in bipolar pulse mode closed loop reactive gas control for oxygen was applied in order to stabilize the reactive working point of the discharge in the so-called transition mode. This allows the highest possible deposition rate at a given power level to be achieved because stoichiometric films can be deposited by sputtering from a near-metallic target at high sputter yield. The $\mathrm{SiO}_{2}, \mathrm{Si}_{3} \mathrm{~N}_{4}$, AIN and $\mathrm{Al}_{2} \mathrm{O}_{3}$ films investigated in this paper were deposited at typically $7 \mathrm{~kW}$ power with deposition rates of approximately $200 \mathrm{~nm} / \mathrm{min}$ for $\mathrm{SiO}_{2}$, AlN and $\mathrm{Al}_{2} \mathrm{O}_{3}$ and $80 \mathrm{~nm} / \mathrm{min}$ for $\mathrm{Si}_{3} \mathrm{~N}_{4}$. 


\section{Piezoelectric AIN films}

AIN films were deposited in unipolar and bipolar mode varying deposition pressure, reactive working point and the pulse parameter duty cycle. The films were investigated in the SEM concerning morphology, in the XRD concerning crystalline structure and in a $d_{33}$ meter concerning the piezoelectric coefficient $d_{33}$. Results showed a strong correlation between $d_{33}$ and the crystalline structure. Only films with an nearly pure 002 crystalline orientation showed a remarkable piezoelectric activity. Surprisingly, in both pulse modes films with strong piezoelectric activity could be achieved despite the significant differences in energetic ion bombardment of the growing film. However in both cases the parameter window for obtaining strong piezoelectric activity was very narrow and required some effort to reproduce.

Table 2 gives an overview on the film properties in both pulse modes. Fig. 3 and 4 give the XRD and SEM of AIN films deposited in bipolar pulse mode. Measurements of $d_{33}$ in this paper were conducted at room temperature. Investigations for higher temperatures are presently carried out. Literature data suggests that piezoelectric AIN films exhibit a very use temperature of over $1000^{\circ} \mathrm{C}$ [3].

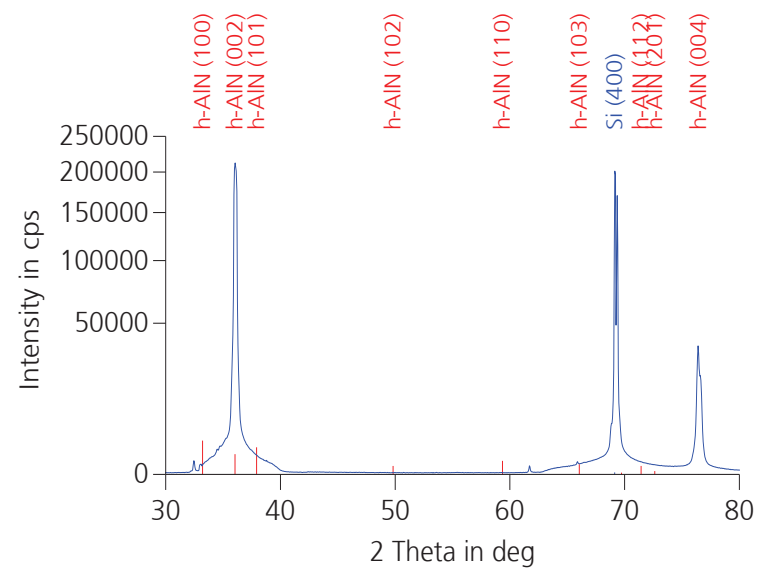

Fig 3: XRD of AIN film deposited in bipolar pulse mode

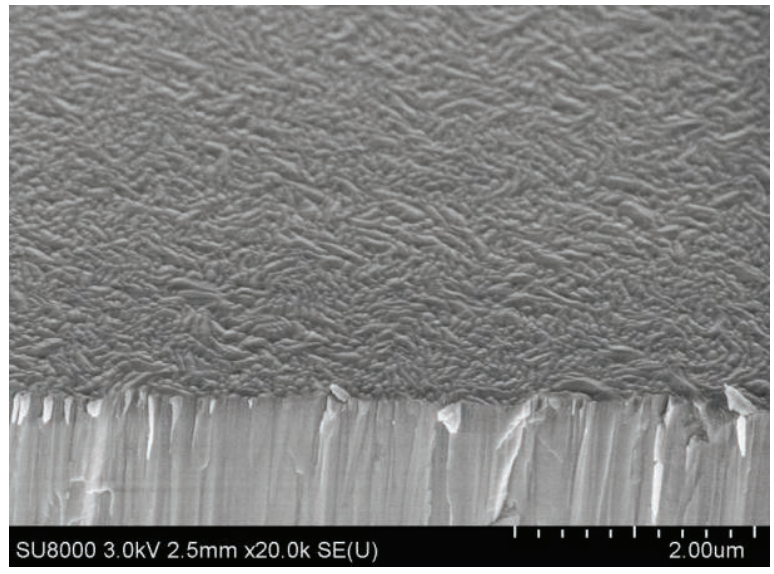

Fig 4: SEM of AIN film deposited in bipolar pulse mode

Table 2: Properties of AIN films deposited in unipolar and bipolar pulse mode

\begin{tabular}{|l|l|l|}
\hline Deposition rate & $3.5 \mathrm{~nm} / \mathrm{sec}$ & $2.5 \mathrm{~nm} / \mathrm{sec}$ \\
\hline Crystalline orientation & $002(99,9 \%)$ & $002(99,9 \%)$ \\
\hline Density & $3.16 \mathrm{~g} / \mathrm{cm}^{3}$ & $3.20 \mathrm{~g} / \mathrm{cm}^{3}$ \\
\hline Break down field strength & $2.3 \mathrm{MV} / \mathrm{cm}$ & $3.1 \mathrm{MV} / \mathrm{cm}$ \\
\hline Resistivity & $5.3 \mathrm{E}+12 \Omega \mathrm{cm}$ & $1.2 \mathrm{E}+13 \Omega \mathrm{cm}$ \\
\hline $\mathrm{d}_{33}$ & $6.5 \mathrm{pm} / \mathrm{V}$ & $7.2 \mathrm{pm} / \mathrm{V}$ \\
\hline Film stress & $-1 \mathrm{GPa}$ & $-2 \mathrm{GPa}$ \\
\hline
\end{tabular}

\section{Electrically insulating $\mathrm{Al}_{2} \mathrm{O}_{3}, \mathrm{SiO}_{2}$ and $\mathrm{Si}_{3} \mathrm{~N}_{4}$ films}

Electrical insulation properties were determined by applying electrodes of $25 \mathrm{~mm}^{2}$ on top of $\mathrm{Al}_{2} \mathrm{O}_{3}, \mathrm{SiO}_{2}$ and $\mathrm{Si}_{3} \mathrm{~N}_{4}$ films and measuring resistivity and break down field strength between the electrode and the $\mathrm{Si}$ wafer. Results are given in Table 3. $\mathrm{SiO}_{2}$ films show better insulation properties when deposited in bipolar rather then in unipolar pulse mode. $\mathrm{Al}_{2} \mathrm{O}_{3}$ film properties are slightly better in unipolar pulse mode. $\mathrm{Si}_{3} \mathrm{~N}_{4}$ films show slightly inferior insulation properties compared to the other films but may be useful for example as moisture protection.

Measurements at $400^{\circ} \mathrm{C}$ substrate temperature were carried out by applying the same electrodes onto the steel membranes of pressure sensors. The yield during testing 50 electrodes by applying a test voltage of 250,500 and $800 \mathrm{~V}$ was measured at room temperature and at $400^{\circ} \mathrm{C}$. Fig. 5 gives the result of these measurements. Yield at $400^{\circ} \mathrm{C}$ is only slightly lower then at room temperature. Surprisingly, pure $\mathrm{SiO}_{2}$ and $\mathrm{Al}_{2} \mathrm{O}_{3}$ layers show slightly better insulating properties than the $\mathrm{SiO}_{2}-\mathrm{Si}_{3} \mathrm{~N}_{4}-\mathrm{Al}_{2} \mathrm{O}_{3}$ layer stack. We 
attribute this effect to electronic defects that are present at the layer interfaces. However, the $\mathrm{SiO}_{2}-\mathrm{Si}_{3} \mathrm{~N}_{4}$ $\mathrm{Al}_{2} \mathrm{O}_{3}$ layer stack also fulfills the thermo -mechanical and diffusion barrier requirements.

Because of the good temperature stability the insulation layers may therefore have potential applications in automotive and aviation technology where stability at elevated temperatures is required. One example application is the direct pressure measurement in the combustion chamber of vehicle engines.

Table 3: Deposition rate and insulation properties of $\mathrm{Al}_{2} \mathrm{O}_{3}, \mathrm{SiO}_{2}$ and $\mathrm{Si}_{3} \mathrm{~N}_{4}$ films, measured at room temperature on silicon wafer, film thickness $1 \mu \mathrm{m}$

\begin{tabular}{|l|l|l|l|l|}
\hline Material & $\begin{array}{l}\text { Pulse } \\
\text { mode }\end{array}$ & $\begin{array}{l}\text { Deposition rate } \\
{[\mathrm{nm} / \mathrm{min}]}\end{array}$ & $\begin{array}{l}\text { Resistivity } \\
{\left[\Omega^{*} \mathrm{~cm}\right]}\end{array}$ & $\begin{array}{l}\text { Break down field strength } \\
{[\mathrm{MV} / \mathrm{cm}]}\end{array}$ \\
\hline $\mathrm{SiO}_{2}$ & unipolar & 230 & $3,2^{*} 10^{15}$ & 4,3 \\
\hline & bipolar & 150 & $6,3^{*} 10^{16}$ & 5,6 \\
\hline $\mathrm{Al}_{2} \mathrm{O}_{3}$ & unipolar & 150 & $2,3^{*} 10^{16}$ & 6,2 \\
\hline & bipolar & 70 & $2,0^{*} 10^{16}$ & 5,1 \\
\hline $\mathrm{Si}_{3} \mathrm{~N}_{4}$ & bipolar & 80 & $5,2^{*} 10^{13}$ & 2,4 \\
\hline
\end{tabular}

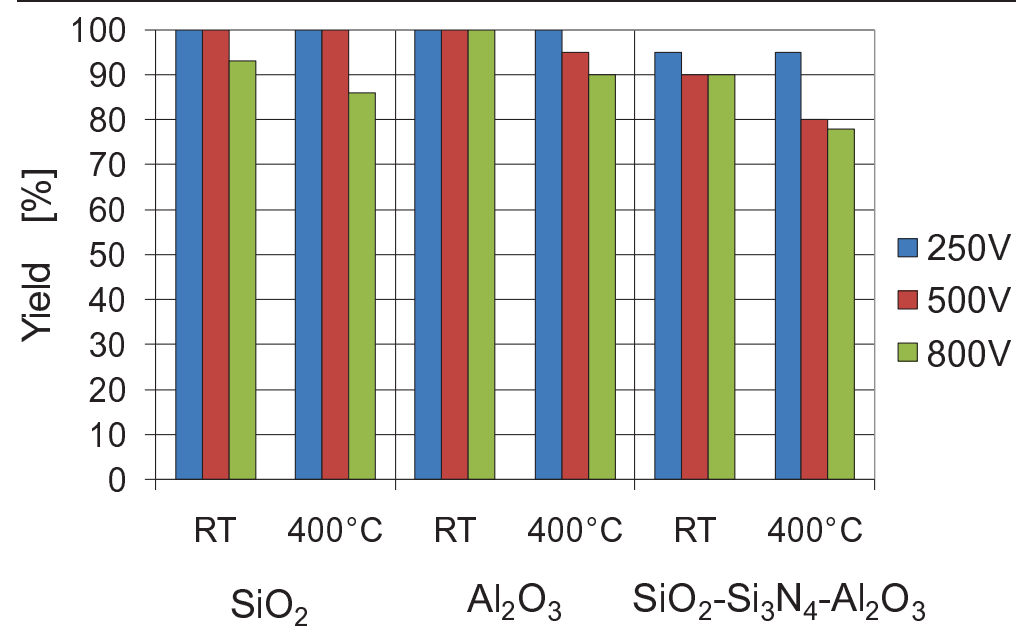

Fig. 5: Comparison of yield during testing at different probe voltages, measurement at room temperature and $400^{\circ} \mathrm{C}$, steel substrate, film thickness $8 \mu \mathrm{m}$

Besides the requirement on high operation temperature there is in some cases also the requirement on stability during following process steps at high temperature. When deposited at room temperature $\mathrm{Al}_{2} \mathrm{O}_{3}$ coatings are amorphous. If in following steps a temperature of $650^{\circ} \mathrm{C}$ is exceeded, the $\mathrm{Al}_{2} \mathrm{O}_{3}$ films start to become $\gamma$-crystalline. This is associated with a volume contraction and hence cracks formation in the film. Figure 6 shows for example a photo obtained by light microscopy of an $\mathrm{Al}_{2} \mathrm{O}_{3}$ film on a steel substrate after a heat treatment of 4 hours at $750^{\circ} \mathrm{C}$ in atmosphere.

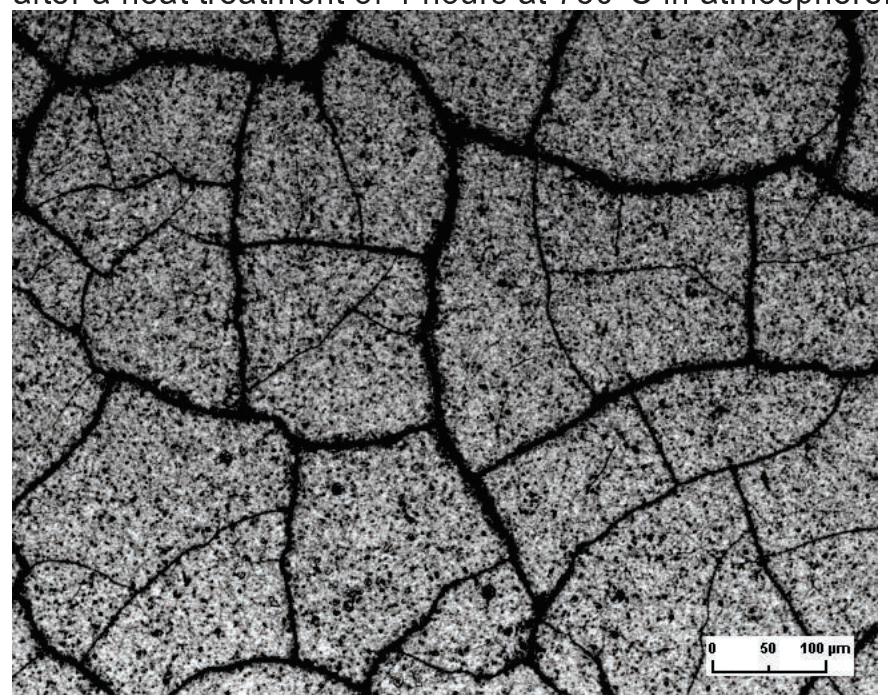

Fig 6: Light microscope photo of $\mathrm{Al}_{2} \mathrm{O}_{3}$ film on steel substrate after heat treatment of $750^{\circ} \mathrm{C}, 4 \mathrm{~h}$ on atmosphere 


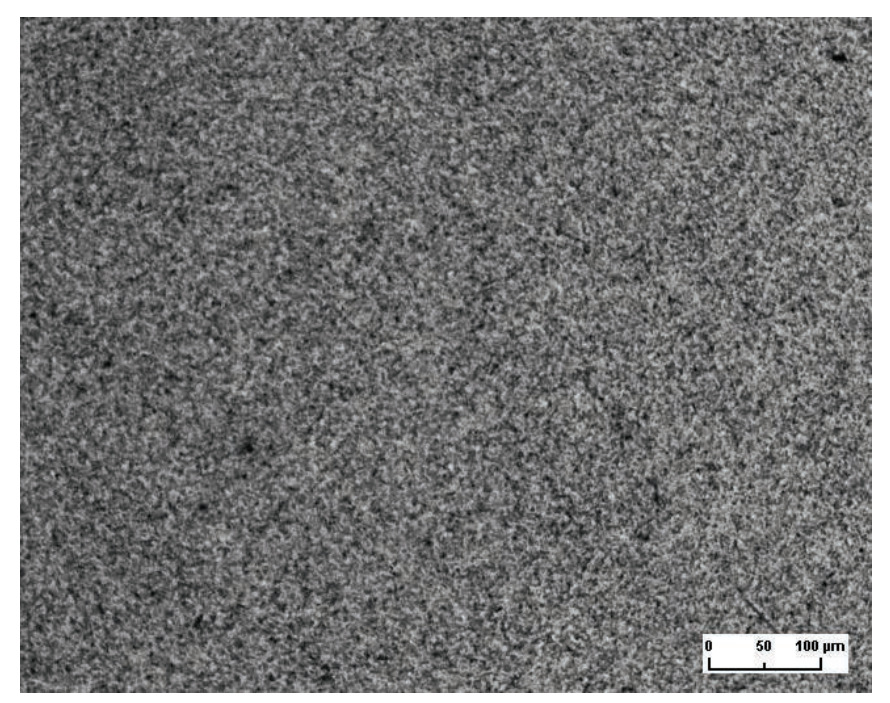

Fig 7: Light microscope photo of $\mathrm{Al}_{2} \mathrm{O}_{3}: \mathrm{SiO}_{2}(10 \%)$ film on steel substrate after heat treatment of $800^{\circ} \mathrm{C}, 4 \mathrm{~h}$ on atmosphere

Because some applications require downstream process steps at $650 \ldots 800^{\circ} \mathrm{C}$ it is desirable to increase crystallization temperature of $\mathrm{Al}_{2} \mathrm{O}_{3}$. During a series of experiments it was tested, whether the incorporation of a small amount of $\mathrm{SiO}_{2}$ into the $\mathrm{Al}_{2} \mathrm{O}_{3}$ could help to rise crystallization temperature. Incorporation of $\mathrm{SiO}_{2}$ was accomplished by the introduction of $\mathrm{SiH}_{4}$ or HMDSO as additional process gases into the deposition chamber during reactive sputtering, by reactive co-sputtering from $\mathrm{Al}$ and $\mathrm{Si}$ targets or by using an $\mathrm{AlSi}(5 \%)$ target for reactive sputtering. With these methods $\mathrm{Al}_{2} \mathrm{O}_{3}: \mathrm{SiO}_{2}$ films were obtained with an $\mathrm{SiO}_{2}$ content varying between 4 and $10 \%$. All of these films did not crystallize during the heat tretatment of 4 hours at $800^{\circ} \mathrm{C}$ in atmosphere. Figure 7 shows for example the photograph of a $\mathrm{Al}_{2} \mathrm{O}_{3}: \mathrm{SiO}_{2}(10 \%)$ after heat treatment. This film was obtained by adding HMDSO during the reactive sputtering.

Fig. 8 displays the evaluation of yield concerning electrical insulation of an $\mathrm{Al}_{2} \mathrm{O}_{3}: \mathrm{SiO}_{2}(4 \%)$ film as deposited and after the heat treatment. This film was deposited by reactive sputtering from an $\mathrm{AlSi}(5 \%)$ target. Fig. 8 shows, that the heat treatment leads to a significant reduction of yield especially at the test voltage of $800 \mathrm{~V}$. However, films are still good insulators.

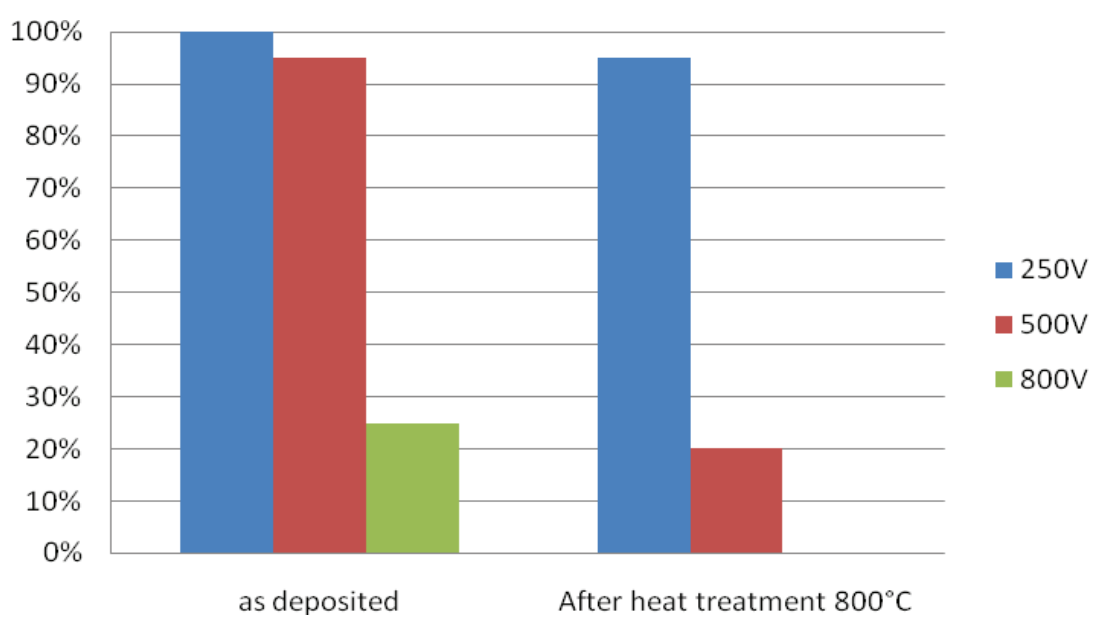

Fig. 8: Yield of $\mathrm{Al}_{2} \mathrm{O}_{3}: \mathrm{SiO}_{2}(4 \%)$ films during testing at different probe voltages, measurement at room temperature as deposited and after heat treatment at $800^{\circ} \mathrm{C}$, steel substrate, film thickness $4 \mu \mathrm{m}$ 


\section{$\mathrm{Al}_{2} \mathrm{O}_{3}, \mathrm{SiO}_{2}$ and $\mathrm{Si}_{3} \mathrm{~N}_{4}$ as barrier films}

Barrier properties were measured according to ISO 15106-03 using electrolytic method with tester WDDG of company Brugger. Measurement area was $78,5 \mathrm{~cm}^{2}$. Table 4 gives an overview of the results. The values of water vapor transmission rate (WVTR) and oxygen transmission rate (OTR) represent the state of the art of sputtered layers on plastic web. Relevant for most applications in sensor technology however is the barrier property on rigid substrates that cannot be measured easily. Therefore from the measurements on foil no clear conclusion can be drawn which layer type and process parameter is best suited for typical sensor applications. Experience shows that especially $\mathrm{Si}_{3} \mathrm{~N}_{4}$ and $\mathrm{Al}_{2} \mathrm{O}_{3}$ are good moisture barriers.

Table 4: Water vapor transmission rate (WVTR) and Oxygen transmission rate (OTR) of $\mathrm{SiO}_{2}, \mathrm{Si}_{3} \mathrm{~N}_{4}$ and $\mathrm{Al}_{2} \mathrm{O}_{3}$ films on $75 \mu \mathrm{m}$ PET

\begin{tabular}{|l|l|l|l|l|}
\hline Material & $\begin{array}{l}\text { Pulse } \\
\text { mode }\end{array}$ & $\begin{array}{l}\text { Film thickness } \\
{[\mathrm{nm}]}\end{array}$ & $\begin{array}{l}\text { Water vapor transmission } \\
\text { rate } \\
{\left[\mathrm{g} / \mathrm{m}^{2} \mathrm{~d}\right]}\end{array}$ & $\begin{array}{l}\text { Oxygen transmission rate } \\
{\left[\mathrm{cm}^{3} / \mathrm{m}^{2} \mathrm{~d} \text { bar }\right]}\end{array}$ \\
\hline PET foil & & & 7,9 & \\
\hline $\mathrm{SiO}_{2}$ & unipolar & 200 & 0,1 & $<0,1$ \\
\hline $\mathrm{SiO}_{2}$ & bipolar & 200 & 0,17 & 0,1 \\
\hline $\mathrm{Si}_{3} \mathrm{~N}_{4}$ & unipolar & 50 & 0,1 & 0,1 \\
\hline $\mathrm{Si}_{3} \mathrm{~N}_{4}$ & bipolar & 50 & 0,12 & $<0,1$ \\
\hline $\mathrm{Al}_{2} \mathrm{O}_{3}$ & unipolar & 200 & 0,022 & $<0,1$ \\
\hline
\end{tabular}

\section{Summary}

Reactive sputtering allows the high rate deposition of many layer materials relevant for sensor applications. AIN films with strong 002 crystalline orientation show significant piezoelectric activity. $\mathrm{Al}_{2} \mathrm{O}_{3}, \mathrm{Si}_{3} \mathrm{~N}_{4}$ and $\mathrm{SiO}_{2}$ films are suitable for electrical insulation and barrier applications and show good insulation strength also at an operation temperature of $400^{\circ} \mathrm{C}$. Especially $\mathrm{Al}_{2} \mathrm{O}_{3}$ is interesting for many applications because of its relatively high coefficient of thermal expansion that allows a better adaptation to the typical metal base bodies. Thermal stability of $\mathrm{Al}_{2} \mathrm{O}_{3}$ films could be significantly improved by incorporation of $\mathrm{SiO}_{2}$. An $\mathrm{SiO}_{2}$ content of $5 . .10 \%$ resulted in a shift of crystallization temperature beyond $800^{\circ} \mathrm{C}$. The good temperature resistivity of the coating makes them suitable for applications in harsh environments like combustion chambers or exhaust lines of vehicle engines or measurement in chemical industry or oil production.

\section{References}

[1] P. Frach, Chr. Gottfried, H. Bartzsch, K. Goedicke, Surface Coatings Technology 90 (1997) 75-81

[2] H. Bartzsch, P. Frach, K. Goedicke, Surface Coatings Technology 132 (2000) 244-250

[3] Morito Akiyama, Toshihiro Kamohara, Kazuhiko Kano, Akihiko Teshigahara, Yukihiro Takeuchi, Nobuaki Kawahara, Advanced Materials,Volume 21, Issue 5, pages 593-596, February 2, 2009 